Article

\title{
Synthesis and Characterization of Biodegradable Poly(butyl cyanoacrylate) for Drug Delivery Applications
}

\author{
Benjamin-Luca Keller ${ }^{1, *}$, Claudia A. Lohmann ${ }^{2, *}$, Samuel O. Kyeremateng ${ }^{1}$ and Gert Fricker $^{3}$ (D) \\ 1 AbbVie Deutschland GmbH \& Co. KG, Knollstrasse, 67061 Ludwigshafen, Germany; \\ samuel.kyeremateng@abbvie.com \\ 2 Waters Corporation, 34 Maple Street, Milford, MA 01757, USA \\ 3 Institute of Pharmacy and Molecular Biotechnology, University of Heidelberg, Im Neuenheimer Feld 329, \\ 69120 Heidelberg, Germany; gert.fricker@uni-hd.de \\ * Correspondence: benjamin-luca.keller@abbvie.com (B.-L.K.); claudia_lohmann@waters.com (C.A.L.); \\ Tel.: +49-621-589-2392 (B.-L.K.); +1-508-482-2305 (C.A.L.)
}

check for

updates

Citation: Keller, B.-L.; Lohmann, C.A.; Kyeremateng, S.O.; Fricker, G. Synthesis and Characterization of Biodegradable Poly(butyl cyanoacrylate) for Drug Delivery Applications. Polymers 2022, 14, 998 https://doi.org/10.3390/ polym14050998

Academic Editors: Florian J. Stadler and Alberto García-Peñas

Received: 20 January 2022

Accepted: 26 February 2022

Published: 28 February 2022

Publisher's Note: MDPI stays neutral with regard to jurisdictional claims in published maps and institutional affiliations.

Copyright: (C) 2022 by the authors. Licensee MDPI, Basel, Switzerland. This article is an open access article distributed under the terms and conditions of the Creative Commons Attribution (CC BY) license (https:// creativecommons.org/licenses/by/ $4.0 /)$.

\begin{abstract}
Poly(butyl cyanoacrylate) (PBCA) is a biodegradable and biocompatible homopolymer which is used as a carrier matrix for drug delivery systems in the pharmaceutical industry. Typically, polymerization is carried out under aqueous conditions and results in molecular weights are mostly lower than $3000 \mathrm{~g} / \mathrm{mol}$ due to the instability of the high molecular weight PBCA. However, the stability of polymer excipients is a major prerequisite for drug product development in the pharmaceutical industry. In this work, a reliable polymer synthesis strategy for PBCA was designed to control the molecular weight in a nonaqueous polymerization environment. The anionic polymerization process and the impact of key synthesis parameters were investigated. The results confirmed that the previously postulated depolymerization-repolymerization process (DPRP) in the literature can be used to tailor the molecular weight of PBCA. The amount of sodium methoxide present during the polymerization proved to be the key parameter to control the DPRP and the molecular weight as desired. In addition, it was discovered that end-capping the PBCA chain suppressed the DPRP and prevented monomer release by depriving the PBCA of its living character. Thus, neat PBCA polymer with varying molecular weights determined by Advanced Polymer Chromatography ${ }^{\mathrm{TM}}$ as well as end-capped PBCA were synthesized, and the improvement of the chemical and shelf-life stability were confirmed using NMR.
\end{abstract}

Keywords: drug delivery; PBCA; molecular weights; biodegradable polymers; NMR; Advanced Polymer Chromatography ${ }^{\mathrm{TM}}$

\section{Introduction}

Over the past few decades, nanomedicine has become a promising drug delivery strategy which provides solutions to increase drug substance concentrations at the site of action. The term nanomedicine is associated with the approach to target specific sites of action within a patient with drug-loaded nanoparticles (NP). These include polymeric NP, metal or metal oxide NP, nanocrystals, carbon-based NP, protein NP, lipid NP and liposomes [1-8]. Polymer-based NP have been known and investigated for the past four decades. In particular, polymeric NP comprised of biodegradable polymers derived from synthetic or natural polymers offer a promising approach for targeted drug delivery. Commonly used biodegradable and biocompatible polymers for polymeric NP design include poly(alkyl cyanoacrylates) (PACA) [9]. In 1979, Couvreur et al. reported the generation and characterization of PACA-based NP for the first time [10]. Since then, PACA NP have been extensively studied and frequently published [11,12]. Different PACA types with varying side alkyl groups up to $C 8$ find use for NP production [12]. In the pharmaceutical field, poly(butyl cyanoacrylate) (PBCA) is a common representative of the PACA 
family, frequently studied as a drug delivery system to target cancer and/or pass the bloodbrain barrier [11,13]. PBCA is a homopolymer composed of $n$-butyl-2-cyanoacrylate (BCA) monomer units. The monomer is successfully applied as a biomedical tissue adhesive due to the fast polymerization mechanism [14]. However, the lack of commercially available PBCA bears a challenge for the production of PBCA-based drug delivery systems. Thus, PBCA must be synthesized from the monomer prior to NP production. This distinguishes PBCA NP considerably from other polymeric NP systems (e.g., poly(lactic-co-glycolide) or poly(caprolactone)), where the polymer matrices are commercially available.

PBCA can generally be considered a pharmaceutical excipient; therefore, it has to meet the requirements regarding safety, functionality and quality $[15,16]$. The lack of commercially available PBCA has so far been compensated by applying BCA polymerization-based NP production methods where the in situ formation of polymer and nanoparticles take place simultaneously $[11,12]$. Within this approach, the anionic living polymerization is the predominant polymerization method for the synthesis of PBCA. The anionic polymerization of PBCA and its mechanism was intensively studied by Pepper et al. [17]. Although this polymerization-based method is mainly used to generate PBCA NP in the pharmaceutical field, the one-step process has two main drawbacks:

1. The characterization of PBCA as a defined pharmaceutical excipient to ensure quality prior to the NP formation is not possible;

2. The solvent-dependent molecular weight (MW) control insufficiency of PCBA during polymerization.

Within the pharmaceutical field, BCA is usually polymerized under aqueous conditions. In an aqueous medium, the formation of oligomeric units is favored, yielding a MW range of 1000-3000 g/mol [18]. Based on the literature, no polymeric NP-based delivery systems composed of PBCA exceed a MW of $3000 \mathrm{~g} / \mathrm{mol}$. However, in the field of polymeric NP, PBCA with higher MW is of great interest, since it was shown that the MW of biodegradable polymers can influence the physicochemical properties of the NP and thereby impact their performance after administration [19-21].

The reason for the insufficient polymerization control in an aqueous environment can be attributed to the high reactivity of the monomer's chemical structure. The $\beta$-carbonyllike structure of alkyl cyanoacrylates has a preferred tendency to form carbanions which undergo resonance stabilization induced by the strong electronegativity of the nitrile and carbonyl group (Figure 1A). This potent electron-withdrawing tendency increases the terminal C-H acidity as the chain length of the polymer increases (Figure 1B). Carbanion stabilization lends an exceptionally high reactivity to the monomer. The $\mathrm{C}-\mathrm{H}$ acidity contributes to the living character of a PBCA molecule, enabling the polymer chain to restructure depending on the surrounding environment [18].

However, Pepper et al. showed that it is also possible to perform a living polymerization of PBCA in anhydrous THF as a polymerization medium $[17,22]$. Trace amounts of anions and weak bases such as hydroxides, alcohols, amines, etc., are sufficient to initiate the polymerization of PBCA. Furthermore, the researchers discovered a polymerizationinhibiting effect of strong acids that could also retard the polymerization of BCA [23,24]. The inhibition is caused by an excess of protons neutralizing the number of basic molecules in the reaction mixture as well as carbanion formation by covalently bonding to the $\alpha$ carbon. Other possible polymerization mechanisms for PBCA are zwitterionic and radical polymerization. These are rarely performed in the pharmaceutical industry [25-27] because anionic polymerization always occurs as a side reaction.

Putting a strong focus on developing a reliable synthesis process for PBCA as an excipient calls for separating the synthesis process from the nanoparticle formation process in order to independently control the MW of PBCA. Therefore, in this work, the anionic polymerization mechanism of $\mathrm{PBCA}$ was studied and key polymerization process parameters were investigated and varied. The evolution of the polymerization process was monitored by Advanced Polymer Chromatography ${ }^{\mathrm{TM}}\left(\mathrm{APC}^{\mathrm{TM}}\right)$, determining the MW of the polymer at different stages of the polymerization process. APC ${ }^{\mathrm{TM}}$ is an UPLC-like instrument that 
is utilized for size-based separations, offering the unique capability of high-resolution analysis. Due to its ability to resolve low MW species down to the monomer level, APC ${ }^{\mathrm{TM}}$ proves to be a valuable tool for analyzing the changes during polymerization. The short runtimes of a single measurement also allow for a high sample throughput. NMR was used to verify the chemical structure of PBCA and monitor the postsynthesis end-capping functionalization of PBCA.

A

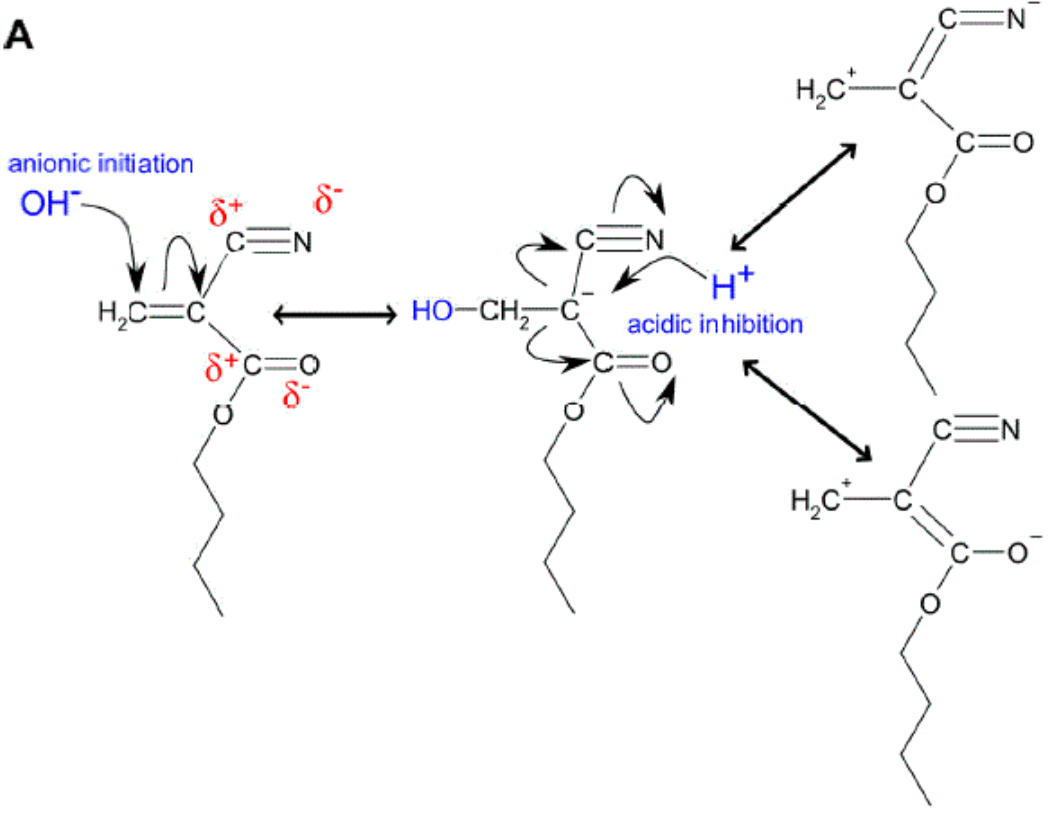

B

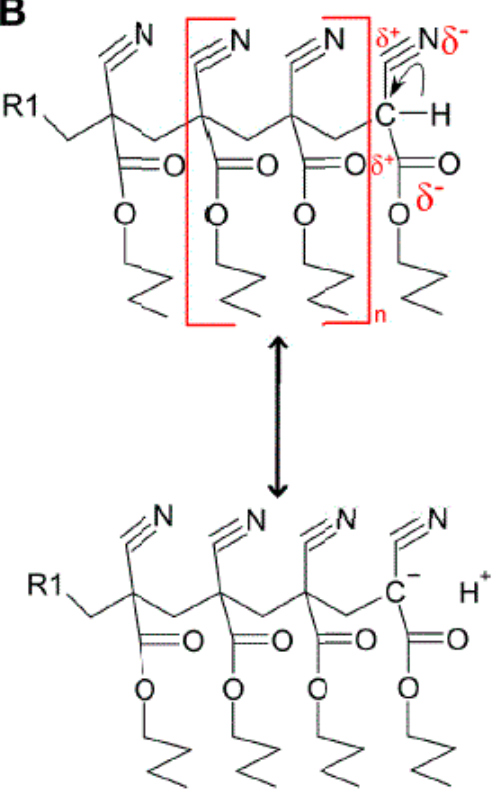

Figure 1. (A) Chemical structure of $\mathrm{BCA}$, including possible resonance structures; (B) Chemical structures of PBCA and the origin of the $\mathrm{C}-\mathrm{H}$ acidity appearing on the chain terminus of the polymer.

The overall aim of this work was to control and optimize the anionic polymerization process for PBCA to allow tailoring of the polymer MW. Keeping in mind that PBCA can potentially be applied as a pharmaceutical excipient for drug delivery, we further investigated the MW effect on the chemical stability of PBCA and end-capped PBCA.

\section{Materials and Methods}

\subsection{Chemicals}

Indermil ( $n$-butyl cyanoacrylate monomer, BCA) was obtained from Henkel (Düsseldorf, Germany). AcroSeal ${ }^{\mathrm{TM}}$ tetrahydrofuran (THF) $99.5 \%$ extra dry was purchased from Acros Organics (Geel, Belgium) and trifluoroacetic acid (TFA) was purchased from Omnilab (Bremen, Germany). Sodium methoxide $(\mathrm{NaOMe})$ powder, deuterated chloroform $\left(\mathrm{CDCl}_{3}\right)$ and ethyl 2-(bromomethyl) acrylate (EBMA) were obtained from Sigma-Aldrich (Taufkirchen, Germany). A total of $0.1 \mathrm{M}$ hydrochloric acid ( $\mathrm{HCl})$, chloroform (HPLC grade), methanol (HPLC grade), acetonitrile (HPLC grade) and HPLC-grade water were purchased from Merck (Darmstadt, Germany).

\subsection{Characterization Techniques}

\subsubsection{Advanced Polymer Chromatography ${ }^{\mathrm{TM}}\left(\mathrm{APC}^{\mathrm{TM}}\right)$}

ACQUITY $^{\mathrm{TM}}$ APC $^{\mathrm{TM}}$ from Waters Corporation (Milford, MA, USA) was used with a column bank consisting of an ACQUITY ${ }^{\mathrm{TM}}$ BEH XT $200(4.6 \mathrm{mM} \times 150 \mathrm{mM}, 2.5 \mu \mathrm{m})$ connected to two ACQUITYTM BEH XT $45(4.6 \mathrm{mM} \times 150 \mathrm{mM}, 1.7 \mu \mathrm{m})$ in series at $40^{\circ} \mathrm{C}$. THF was used as a mobile phase at a flow rate of $1 \mathrm{~mL} / \mathrm{min}$. Refractive index was used as a detector for the chromatograms. Conventional calibration was conducted with polystyrene standards. MW calculations were conducted with Empower ${ }^{\mathrm{TM}}$ with GPC option. Samples 
were dissolved in THF to make a final concentration of $5 \mathrm{mg} / \mathrm{mL}$ and $10 \mu \mathrm{L}$ of the solution injected for the measurements.

\subsubsection{NMR}

The $600 \mathrm{MHz}{ }^{1} \mathrm{H}$ and $150 \mathrm{MHz}{ }^{13} \mathrm{C}$ NMR spectra were obtained with a Bruker Avance ${ }^{\mathrm{TM}}$ system (Karlsruhe, Germany). Approximately $5 \mathrm{mg}$ of samples were dissolved in $600 \mu \mathrm{L}$ deuterated chloroform $\left(\mathrm{CDCl}_{3}\right)$ for the measurements.

\subsection{Synthesis}

\subsubsection{Anionic Polymerization in THF}

TFA diluted in $5 \mathrm{~mL}$ of THF was mixed with BCA in $20 \mathrm{~mL}$ scintillation vials. A total $120 \mu \mathrm{L}$ of an aqueous solution of $\mathrm{NaOMe}$ was added under continuous magnetic stirring according to Table 1 . Stirring at room temperature was continued for $180 \mathrm{~min}$. Within this period, samples were taken at different time points and the polymerization was quenched immediately by precipitation in $0.1 \mathrm{M} \mathrm{HCl}(\mathrm{pH} 1)$. The precipitates were frozen on dry ice and then lyophilized in an Alpha LSC 2-4 freeze dryer from Martin Christ (Osterode am Harz, Germany). Primary drying in the freeze dryer was performed for $12 \mathrm{~h}$ at $0.37 \mathrm{mbar}$ with a shelf temperature of $0^{\circ} \mathrm{C}$. Secondary drying was done for $1 \mathrm{~h}$ at $0.01 \mathrm{mbar}$ with a shelf temperature of $10^{\circ} \mathrm{C}$.

Table 1. Conditions during anionic polymerization in THF.

\begin{tabular}{cccc}
\hline Condition & TFA $(\mathbf{m M})$ & BCA $(\mathbf{m M})$ & NaOMe $(\mathbf{m M})$ \\
\hline 1 & 0.00 & 326 & 0 \\
2 & 0.01 & 326 & 5 \\
3 & 1.00 & 326 & 5 \\
4 & 1.00 & 326 & 8 \\
5 & 1.00 & 326 & 100 \\
6 & 1.00 & 653 & 8 \\
7 & 2.00 & 326 & 0.125 \\
8 & 2.00 & 326 & 0.630 \\
9 & 2.00 & 326 & 10 \\
10 & 2.00 & 326 & 20 \\
11 & 2.00 & 326 & 40 \\
12 & 2.00 & 326 & 75 \\
13 & 2.00 & 326 & 80 \\
\hline
\end{tabular}

\subsubsection{PBCA End-Capping with EBMA in THF}

A total of $2 \mathrm{mM}$ TFA diluted in $5 \mathrm{~mL}$ THF was mixed with a $326 \mathrm{mM}$ BCA solution under continuous magnetic stirring. The polymerization was started by adding $120 \mu \mathrm{L}$ of an aqueous $8 \mathrm{mM}$ or $80 \mathrm{mM} \mathrm{NaOMe}$ solution. Stirring was continued for $3 \mathrm{~h}$. An amount of $2.5 \mathrm{~mL}$ of a $5 \mathrm{mM}$ or $25 \mathrm{mM}$ EBMA solution in THF was mixed with $2.5 \mathrm{~mL}$ of the PBCA polymerization mixture. The EBMA-PBCA mixture was stirred for $1 \mathrm{~h}$. The EBMAterminated PBCA (tPBCA) was precipitated in $0.1 \mathrm{M} \mathrm{HCl}(\mathrm{pH} 1)$, purified by filtration and washed with deionized water to remove excess EBMA and lyophilized as described in Section 2.3.1.

\subsubsection{Polymer Stability in Solution}

Approximately $5 \mathrm{mg}$ polymer was dissolved in $600 \mu \mathrm{L}$ deuterated chloroform and stored in a closed glass vial for seven weeks at room temperature. A $600 \mathrm{MHz}{ }^{1} \mathrm{H} \mathrm{NMR}$ spectrum was recorded each week.

\section{Results}

\subsection{Polymerization Process Monitoring by APC ${ }^{\mathrm{TM}}$}

Following Ryan et al.'s, approach, anionic polymerization was performed in THF [22]. The polymerization design comprised of reacting varying amounts of $\mathrm{NaOMe}, \mathrm{BCA}$ and 
TFA. The evaluated polymerization conditions are reported in Table 1. The APC ${ }^{\mathrm{TM}}$ was used to monitor the evolution of the polymerization process and to investigate the impact of the polymerization condition on the MW of the target PBCA.

As described in Section 2, the BCA was diluted in THF containing TFA, which was used as a polymerization-retarding component. In general, the literature reports acids as polymerization-inhibiting components for the anionic polymerization of BCA $[19,24]$. Protons delivered by acids occupy the $\mathrm{C}-\mathrm{H}$ acidic unit on the BCA structure. Consequently, carbanion formation is prevented and, therewith, the polymerization initiation. Costa et al. distinguished between the "polymerization inhibition" induced by strong acids (such as $\mathrm{H}_{2} \mathrm{SO}_{4}$ or $\mathrm{CF}_{3} \mathrm{SO}_{3} \mathrm{H}$ ) and the "polymerization retardations periods" induced by weaker acids (such as $\mathrm{ClCH}_{2} \mathrm{COOH}$ ) [24]. Thus, the presence of TFA prevented the spontaneous polymerization in the solvent THF before an initiator was added to the BCATHF mixture. The presence of an acid is necessary because BCA has the tendency to self-initiate spontaneous polymerization, particularly in polar solvents such as THF [26].

The addition of different $\mathrm{NaOMe}$ amounts as the polymerization initiator led to the formation of mainly high molecular weight (HMW) PBCA, referred to as the "parent peak", within a minute, as illustrated in Figure 2. Alongside the main HMW population is the low molecular weight (LMW) population, referred to as "daughter peak", as well as a minor population at high retention times. Figure 2 also depicts the time-dependent emergence or growth of the "daughter peak" at the expense of the "parent peak" until all of the latter is consumed.

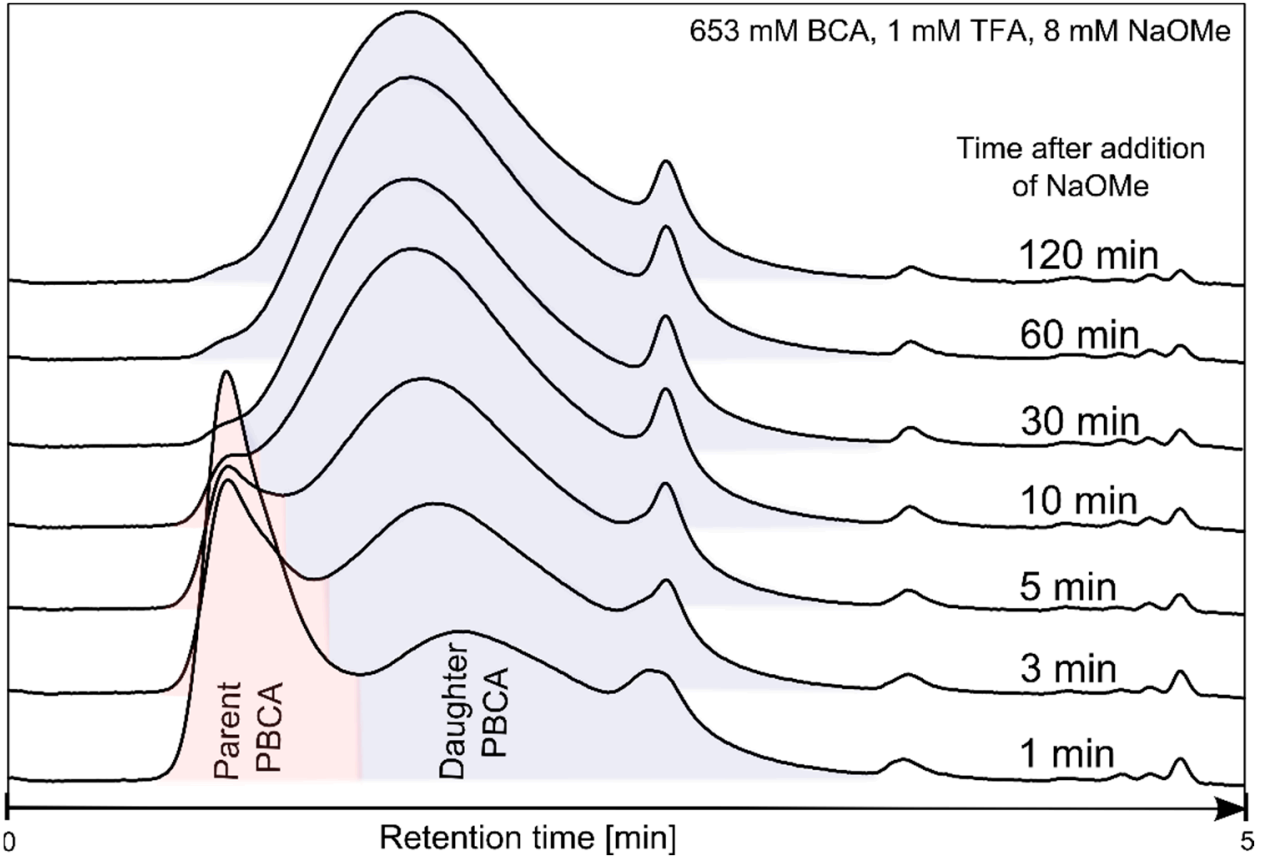

Figure 2. Time-dependent APC ${ }^{\mathrm{TM}}$ chromatograms monitoring the polymerization of PBCA following $\mathrm{NaOMe}$ addition.

This indicates that the initial HMW PBCA underwent depolymerization, exhibited as decrease in the peak intensity and area. Thus, the depolymerization of the parent polymer was accompanied by a simultaneous repolymerization of the unzipped monomer. The distinctive formation, as well as the complete degeneration of the parent PBCA, was strongly dependent on selected polymerization conditions. The restructuring of PBCA from parent to daughter polymer, or the depolymerization-repolymerization process (DPRP), and the subsequent MW changes and relative peak areas are listed in Table 2. Similar observations were first reported by Ryan et al. [22]. The mechanism of the postulated DPRP is displayed in Figure 3. 
Table 2. MW and relative peak area of parent and daughter PBCA as determined by APC ${ }^{\mathrm{TM}}$ (653 $\mathrm{mM}$ BCA, $1 \mathrm{mM}$ TFA and $8 \mathrm{mM} \mathrm{NaOMe})$.

\begin{tabular}{ccccc}
\hline \multirow{2}{*}{ Time (min) } & \multicolumn{2}{c}{ Parent PBCA } & \multicolumn{2}{c}{ Daughter PBCA } \\
\cline { 2 - 5 } & MW (g/mol) & $\begin{array}{c}\text { Relative Peak } \\
\text { Area (\%) }\end{array}$ & MW (g/mol) & $\begin{array}{c}\text { Relative Peak } \\
\text { Area (\%) }\end{array}$ \\
\hline 0.5 & 181,488 & 67 & 645 & 33 \\
1 & 127,605 & 49 & 12,023 & 51 \\
3 & 131,730 & 27 & 15,751 & 73 \\
5 & 145,970 & 15 & 18,775 & 85 \\
10 & 168,314 & 4 & 21,623 & 96 \\
30 & - & 0 & 23,328 & 100 \\
60 & - & 0 & 22,496 & 100 \\
120 & - & 0 & 22,388 & 100 \\
180 & - & 0 & 21,713 & 100 \\
\hline
\end{tabular}

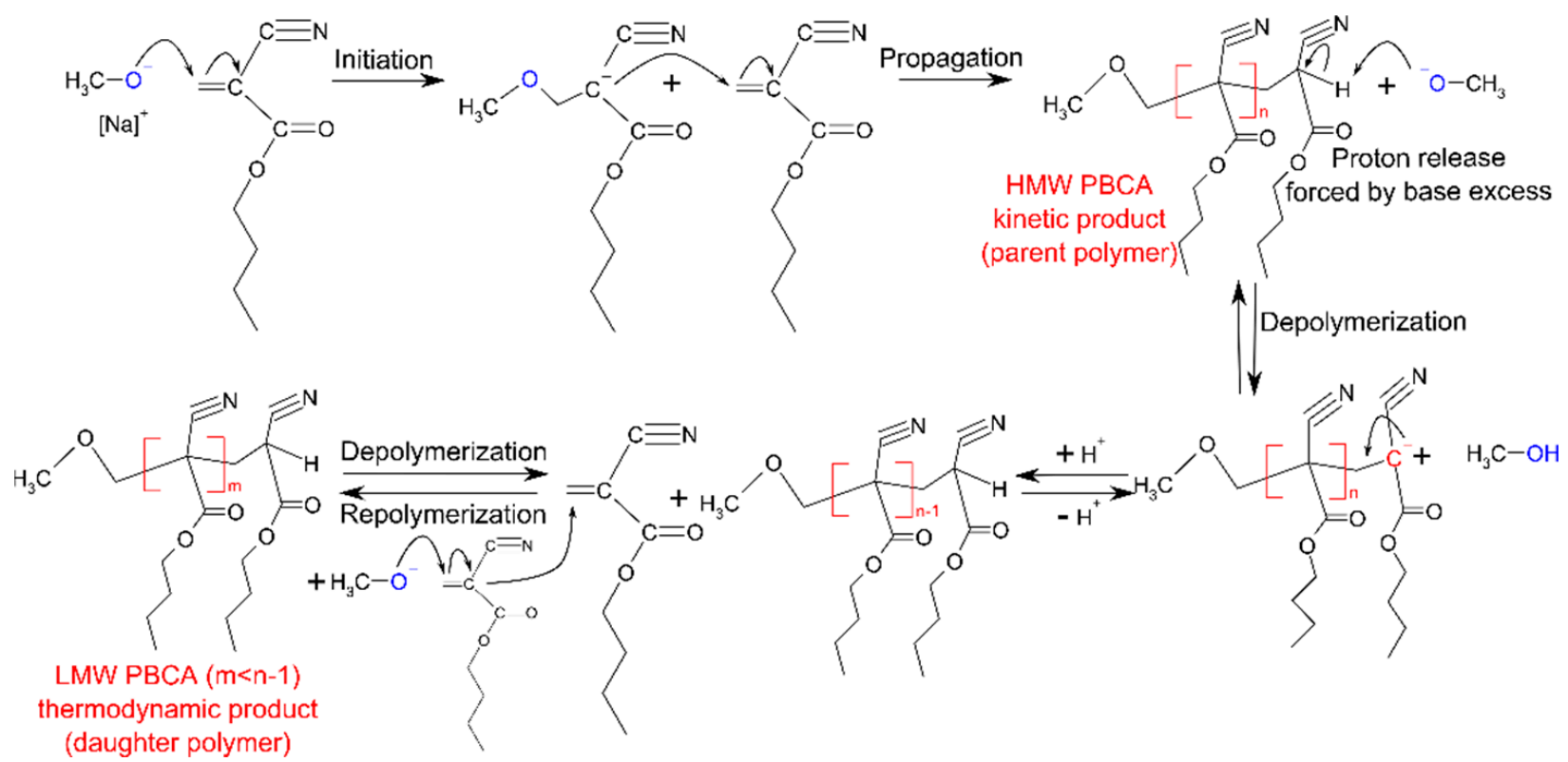

Figure 3. Initiation, propagation and depolymerization-repolymerization steps involved during anionic polymerization of BCA initiated by $\mathrm{NaOMe}$ in THF.

From a postulated mechanistic standpoint, the initial and rate determining step of the DPRP process is the proton liberation from the terminal unit in the polymer chain [22,28]. This proton release induces monomer unzipping from the chain terminus. Ryan et al. concluded from their studies that the excess base can facilitate the proton release and subsequently induce the formation of the LMW daughter PBCA [29]. The excess base forced the polymerization towards a thermodynamic product by deprotonation of the terminal polymer unit and thus reduced the activation energy of the rate-determining step. The researchers described the parent polymer as a kinetic product and the daughter polymer as a thermodynamic product. However, many of the investigated DPRP process conditions in this work resulted in a fluent transition from HMW to LMW PBCA without the appearance of two clearly separated parent and daughter fractions in the APC ${ }^{\mathrm{TM}}$ chromatogram, as can be seen in Figure 4. These transitions, along with the MW changes, appeared as a peak shift in the chromatogram from small retention times resembling HMW parent fractions to high retention times for the LMW daughter fractions. 

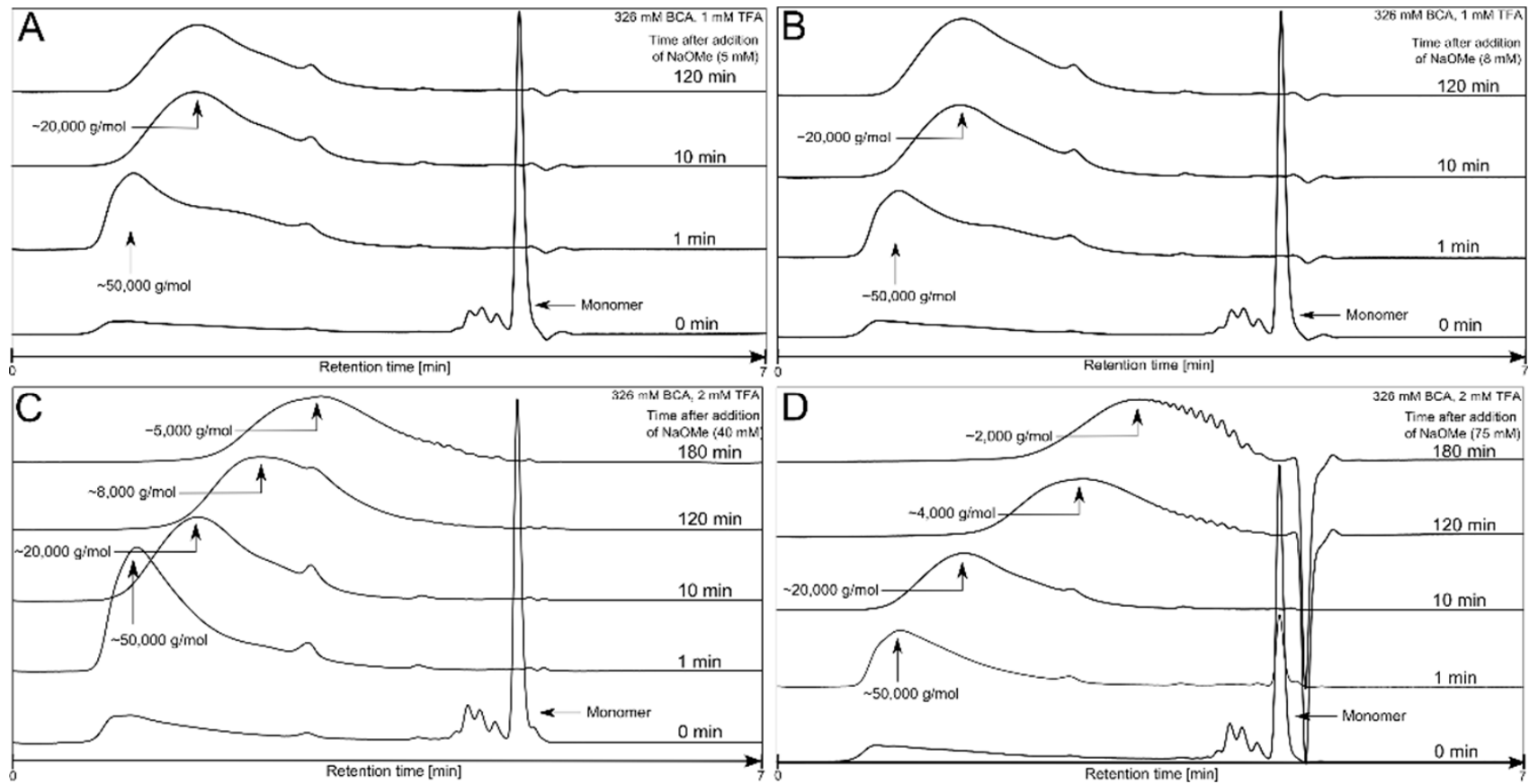

Figure 4. $\mathrm{APC}{ }^{\mathrm{TM}}$ chromatogram of $\mathrm{PBCA}$ at different polymerization time points obtained with $5 \mathrm{mM}$ $\mathrm{NaOMe}$ (A), $8 \mathrm{mM} \mathrm{NaOMe} \mathrm{(B),} 40 \mathrm{mM} \mathrm{NaOMe} \mathrm{(C)} \mathrm{and} 75 \mathrm{mM} \mathrm{NaOMe}$ (D).

The results in Figures 5 and 6 indicate that the DPRP of PBCA is affected by the amounts of $\mathrm{NaOMe}, \mathrm{BCA}$ and TFA. NaOMe at varying amounts had the most profound impact on the DPRP. With increasing amounts of NaOMe, the MW decreased significantly within 180 min of polymerization. The trend of decreasing MW dependent on the $\mathrm{NaOMe}$ amount was observed in all polymerization conditions, as detailed in Figure 5.

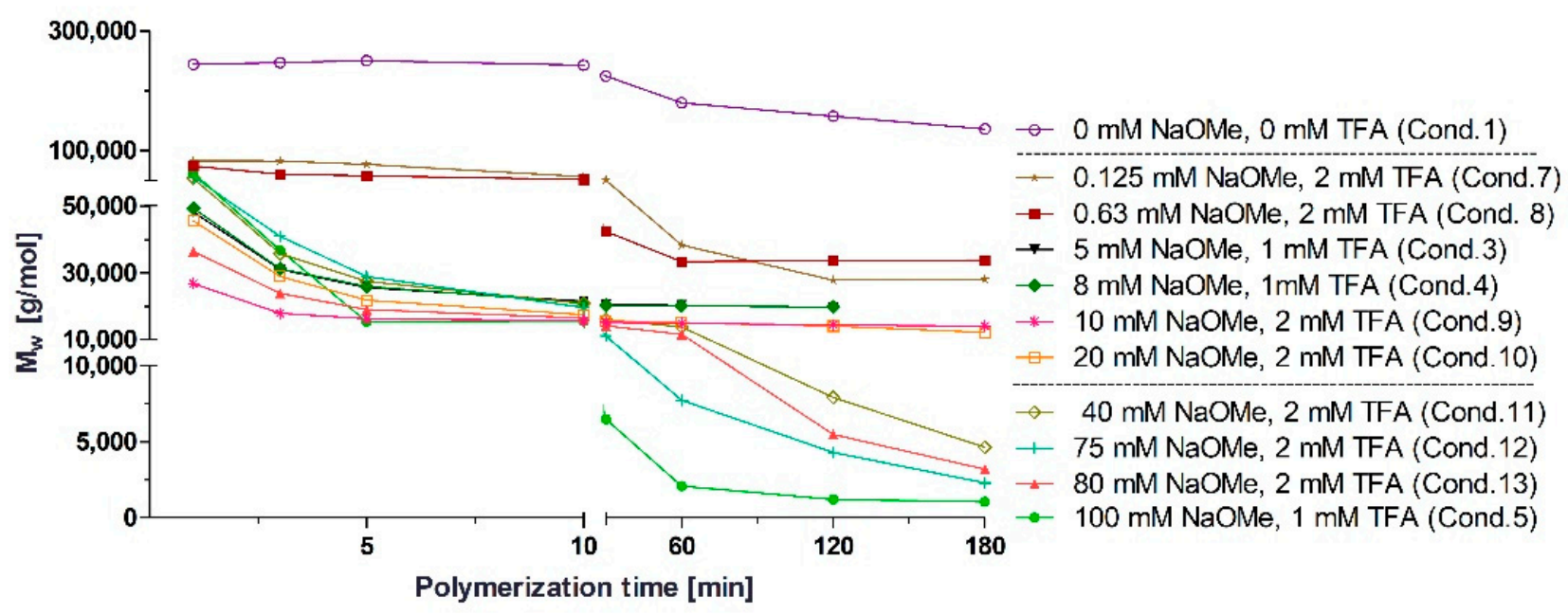

Figure 5. MW changes of PBCA during the anionic polymerization process induced by different NaOMe amounts $(0-100 \mathrm{mM})$. A total of $326 \mathrm{mM} \mathrm{BCA}$ was used in all plotted conditions. MW was determined by $\mathrm{APC}^{\mathrm{TM}}$. 


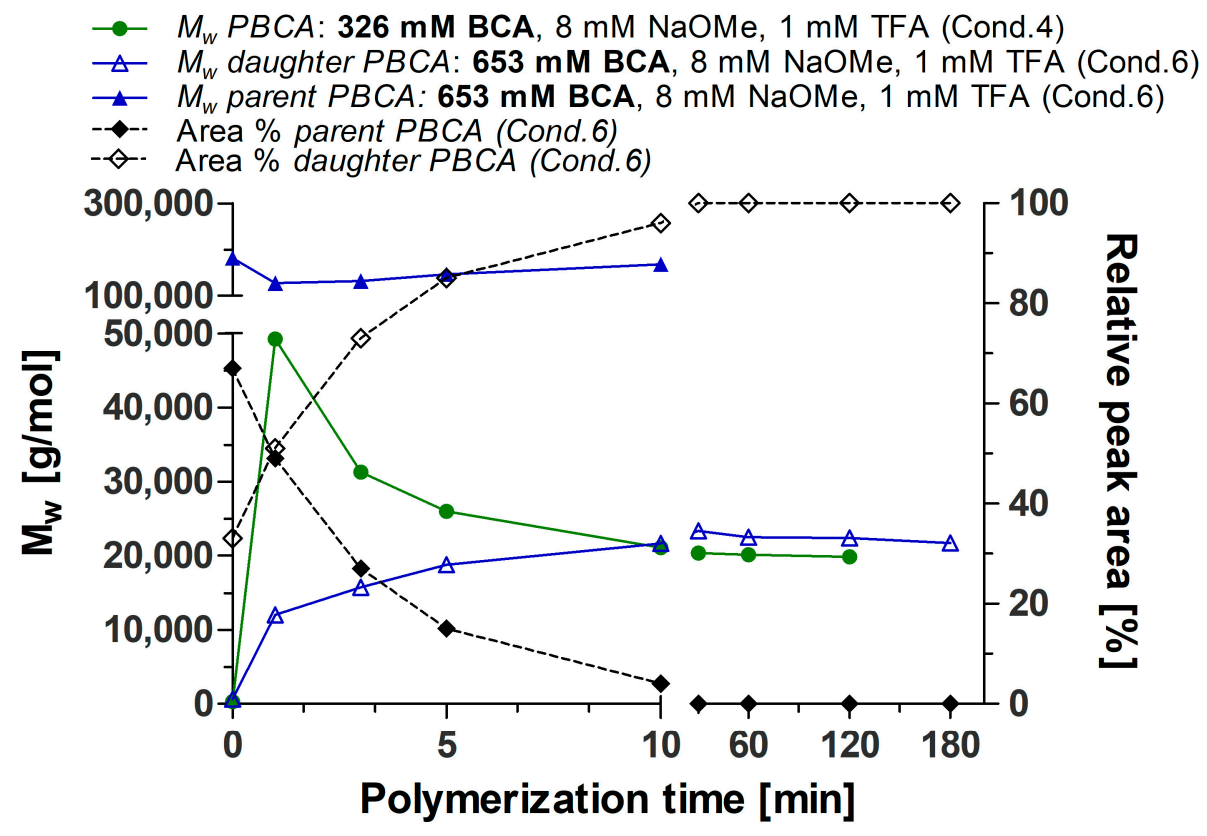

Figure 6. Influence of BCA amount on MW changes during the polymerization process. Comparison between $326 \mathrm{mM}$ BCA and $653 \mathrm{mM}$ BCA, both with $1 \mathrm{mM}$ TFA and $8 \mathrm{mM} \mathrm{NaOMe}$. MW was determined by APC ${ }^{\mathrm{TM}}$.

The outcome of the trend plots (Figures 5 and 6) clearly supports previous studies reporting that the DPRP can be influenced by basic molecules such as TBOH or $\mathrm{NaOMe}[22,30,31]$. The results demonstrate that the effect on the PBCA MW depends on the $\mathrm{NaOMe}$ addition and supports the postulated reaction mechanism of the DPRP in Figure 3. Generally, it can be assumed that any base which can facilitate the proton release will equally reduce the activation energy and consequently force the DPRP towards LMW. Furthermore, different amounts of monomer with fixed amounts of TFA and NaOMe affected the polymerization process. An overall trend plot displaying the MW change induced by varying amounts of BCA is depicted in Figure 6. Polymerization with $326 \mathrm{mM}$ $\mathrm{BCA}, 8 \mathrm{mM} \mathrm{NaOMe}$ and $1 \mathrm{mM}$ TFA led to a fluent PBCA transition without the occurrence of a parent PBCA fraction.

In contrast, increasing the BCA amount $(653 \mathrm{mM})$ decelerated the DPRP, which led to the distinct formation of parent PBCA and daughter PBCA fractions during the polymerization. It can be assumed that a larger monomer amount $(653 \mathrm{mM})$ generated a larger number of HMW PBCA molecules. Hence, under similar conditions, more time is required to depolymerize the large number of HMW fractions compared to the polymerization with 326 mM BCA. Consequently, an increased amount of HMW PBCA molecules will extend the time for the total HMW PBCA consumption and therewith increase the transformation time of HMW PBCA to LMW PBCA. In this case, the HMW PBCA consumption delay prevented a fluent transition and led to the appearance of both fractions in the APC ${ }^{\mathrm{TM}}$ chromatogram. However, the final MW is similar $(20,000 \mathrm{~g} / \mathrm{mol})$ in both the $326 \mathrm{mM}$ and $653 \mathrm{mM}$ BCA trials because the key factor for the final MW at the end of the polymerization is the $\mathrm{NaOMe}$ amount, which was kept constant at $8 \mathrm{mM}$ (Figure 6).

\subsection{NMR}

\subsubsection{PBCA Structure Elucidation}

Two PBCA batches with different MW (2000 g/mol and 20,000 g/mol) were analyzed by ${ }^{13} \mathrm{C}$ and ${ }^{1} \mathrm{H}$ NMR to verify the structure (Figure 7). Additionally, ${ }^{1} \mathrm{H}$ and ${ }^{13} \mathrm{C}$ spectra of the BCA monomer were recorded to identify potential residual monomer units. Both NMR measurements successfully confirmed the PBCA structure [30,32-35]. Differences between the $2000 \mathrm{~g} / \mathrm{mol}$ and 20,000 g/mol PBCA batches in the ${ }^{13} \mathrm{C}$ and ${ }^{1} \mathrm{H}$ spectra appeared 
to be negligible. Therefore, the NaOMe amounts ( $8 \mathrm{mM}$ or $80 \mathrm{mM})$ added to control the MW did not affect the PBCA structure from a chemical perspective. Both spectra revealed some unexpected signals (marked as * in Figure 7) originating from butylated hydroxytoluene (BHT) that stems from the THF polymerization medium. The BHT-laced polymers are indicative of an insufficient purification process at this lab scale and may require optimization in case of scale up. Alternatively, unstabilized BHT-free THF can be utilized instead.

\section{A $\sim 20,000 \mathrm{~g} / \mathrm{mol} \mathrm{PBCA}$}

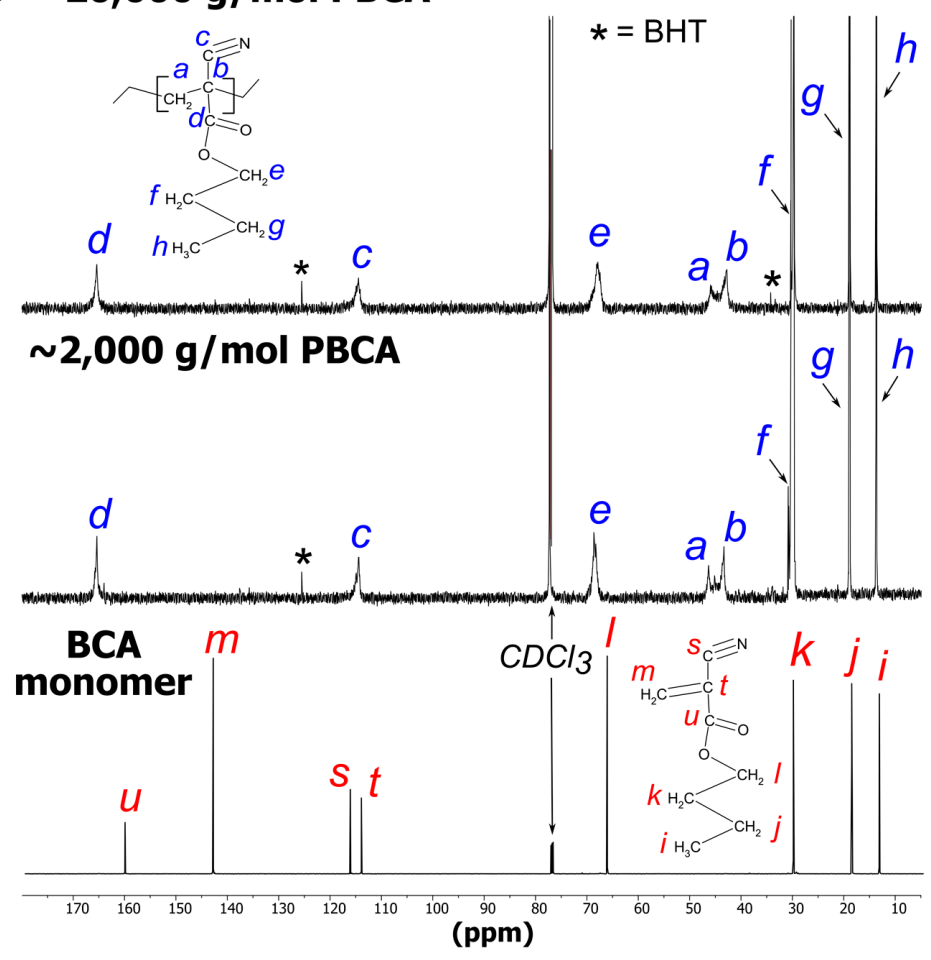

B

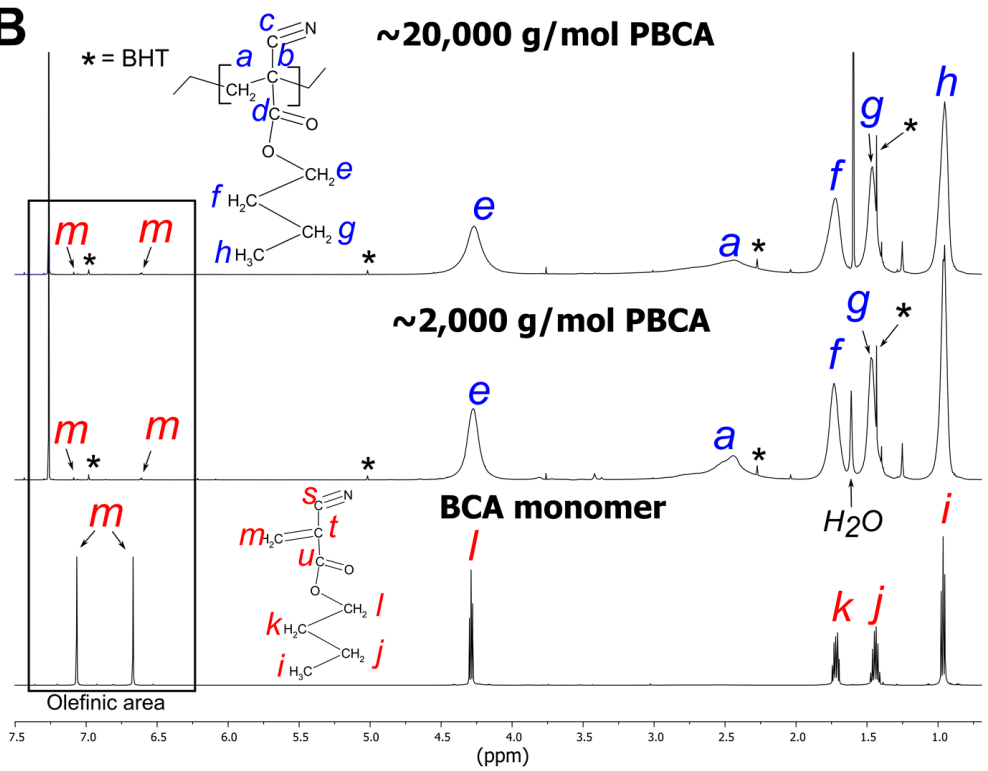

Figure 7. (A) The $150 \mathrm{MHz}{ }^{13} \mathrm{C}$ NMR spectra of $2000 \mathrm{~g} / \mathrm{mol}$ PBCA, 20,000 g/mol PBCA and BCA monomer with molecular structure peak assignments; (B) The $600 \mathrm{MHz}{ }^{1} \mathrm{H}$ NMR spectra of $2000 \mathrm{~g} / \mathrm{mol}$ PCBA, 20,000 g/mol PBCA and monomer with molecular structure peak assignments. Signals associated with butylated hydroxytoluene (BHT) impurity are marked as * 
Signal band broadening in the spectra suggest PBCA to be an atactic polymer (Figure 7A). In addition, the ${ }^{1} \mathrm{H}$ spectra of the $2000 \mathrm{~g} / \mathrm{mol}$ and 20,000 $\mathrm{g} / \mathrm{mol}$ PBCA batches showed very weak signals $(\mathrm{m})$ in the olefinic area at $7.06 \mathrm{ppm}$ and $6.62 \mathrm{ppm}$. Comparing the polymer spectra with the monomer spectrum confirmed that these olefinic signals originated from the monomeric vinyl group $(\mathrm{m})$ (Figure $7 \mathrm{~B}$ ). Similar observations of minor amounts of residual monomer $(\mathrm{m})$ in the ${ }^{1} \mathrm{H}$ spectra in the polymer were also made by other research groups after the polymerization of the alkyl cyanoacrylates [33,36]. The residual monomer amount was negligible and only detectable due to the low detection limit of the ${ }^{1} \mathrm{H}$ NMR measurement. In the ${ }^{13} \mathrm{C}$ NMR measurements, it was not possible to detect the residual monomer due to the lower sensitivity.

\subsection{2. tPBCA Structure Elucidation}

For the systematic investigation of the living polymer character of PBCA, and potentially improving the stability of the PBCA polymer, the $\mathrm{C}-\mathrm{H}$ acidic end group was substituted by EBMA in a postpolymerization reaction, as described by Kohsaka et al. [37]. Briefly, the EBMA acts as an efficient terminator by attacking the living carbanion of PBCA on the vinylidene group of the EBMA, with the subsequent elimination of bromine to generate an unsaturated ester moiety at the polymer end chain. Consequently, the termination with EBMA deprives the PBCA chain of its living character.

Two different MW batches of PBCA with a MW of $2000 \mathrm{~g} / \mathrm{mol}$ and 20,000 g/mol were terminated at two EBMA concentrations, i.e., $25 \mathrm{mM}$ or $5 \mathrm{mM}$. The structure of $\mathrm{tPBCA}$ was analyzed by NMR. The ${ }^{13} \mathrm{C}$ and ${ }^{1} \mathrm{H}$ spectra of tPBCA confirmed the successful linkage of the polymer and the terminal EBMA molecule (Figure 8).
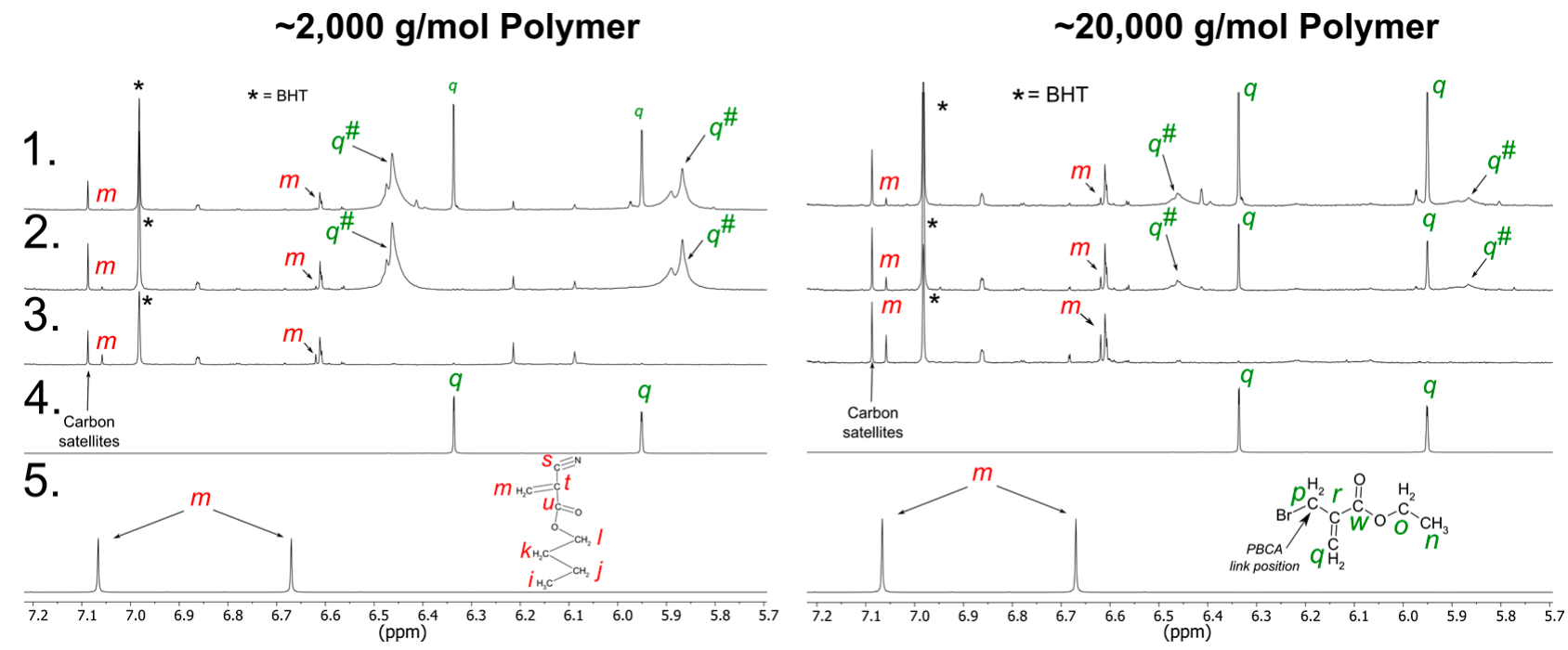

Figure 8. The $600 \mathrm{MHz}{ }^{1} \mathrm{H}$ NMR spectra of the olefinic region. (Left): $\sim 2000 \mathrm{~g} / \mathrm{mol} \mathrm{tPBCA}$ using $25 \mathrm{mM}$ EBMA as terminator (1), 2000 g/mol tPBCA using $5 \mathrm{mM}$ EBMA (2), 2000 g/mol PBCA as comparison (3), neat EBMA (4) and BCA monomer (5). (Right): 20,000 g/mol tPBCA using $25 \mathrm{mM}$ EBMA (1), 20,000 g/mol tPBCA using $5 \mathrm{mM}$ EBMA (2), 20,000 g/mol PBCA as comparison (3), neat EBMA (4) and BCA monomer (5).

Most importantly, the ${ }^{13} \mathrm{C}$ and ${ }^{1} \mathrm{H}$ spectra comparison of PBCA and tPBCA confirmed the integrity of the PBCA backbone structure after the addition of EBMA (Figure $8,{ }^{13} \mathrm{C}$ data not shown). The EBMA vinyl signal in the ${ }^{1} \mathrm{H}$ spectrum was used to monitor the successful reaction between the EBMA and the polymer chain terminus. The different chemical shifts of the EBMA vinyl protons in the tPBCA spectra $\left(q^{\#}\right)$ compared to the neat EBMA spectrum (q) confirmed that EBMA is chemically bonded to PBCA. The two proton signals of $\mathrm{q}^{\#}$ were observed at a higher magnetic and lower magnetic field than the two protons of $q$, thus confirming the linkage between PBCA and EBMA. The observed band 
broadening of $\mathrm{q}^{\#}$ in all the TPBCA samples can again be assigned to the atactic structure of the polymer. However, the q signal from the neat EBMA was still detectable in the ${ }^{13} \mathrm{C}$ and ${ }^{1} \mathrm{H}$ spectra of tPBCA for the $2000 \mathrm{~g} / \mathrm{mol}$ and $20,000 \mathrm{~g} / \mathrm{mol}$ PBCA batches reacted with 25 mM EBMA (Figure 8). Thus, the neat EBMA vinyl group signal in the tPBCA spectra proved the presence of unreacted EBMA molecules. Apparently, 25 mM EBMA bears an excess of the end-capping agent for both MW batches in this trial. A concentration of $5 \mathrm{mM}$ EBMA reacted with the $20,000 \mathrm{~g} / \mathrm{mol}$ PBCA batch also exhibited the neat EBMA vinyl group signal (q) in both ${ }^{13} \mathrm{C}$ and ${ }^{1} \mathrm{H}$ spectra. The $5 \mathrm{mM}$ EBMA reacted with the $2000 \mathrm{~g} / \mathrm{mol}$ batch showed no neat EBMA vinyl group signal (q) in the ${ }^{13} \mathrm{C}$ and ${ }^{1} \mathrm{H}$ tPBCA spectra, indicating a complete reaction between EBMA and the polymer.

These results confirm that the required amount of terminating agent depends on the polymer MW and, consequently, on the number of polymer chain termini. In an equal amount of polymer, the higher MW batch has a lesser number of chain termini compared to the lower MW batch. Consequently, the lower the PBCA MW, the higher the required terminator amount to react with all chain termini. The optimal EBMA amount for the termination of $2000 \mathrm{~g} / \mathrm{mol}$ PBCA is lower than $25 \mathrm{mM}$ and the optimal EBMA amount for the termination of $20,000 \mathrm{~g} / \mathrm{mol}$ is lower than $5 \mathrm{mM}$. However, further studies are necessary to identify the exact EBMA amount required for a specific MW so to avoid residual unreacted EBMA molecules. In addition, the ${ }^{1} \mathrm{H}$ spectra of all the tPBCA samples showed small amounts of residual BCA monomer (m), as described above for the PBCA polymers (Figure 8). The residual monomer probably originated from the NaOMe-induced monomer unzipping reaction during the DPRP prior to the addition of the end-capping agent EBMA. Based on the presence of the monomer in PBCA and IPBCA, a polymer stability study was conducted (see Section 3.2.3) to monitor the possible monomer release in PBCA and IPBCA, and to assess the stability, and thus the potential shelf-life of the polymers.

\subsubsection{Polymer Stability in Solution}

The stability of PBCA was monitored by measuring the increase of the monomer signal in the ${ }^{1} \mathrm{H}$ NMR spectra. A signal increase over time would indicate potential chemical structural changes such as chain deconstruction or degradation. Two batches of neat PBCA and corresponding tPBCA having a MW of $2000 \mathrm{~g} / \mathrm{mol}$ and 20,000 g/mol, respectively, were stored in $\mathrm{CDCl}_{3}$ solution for seven weeks. The ${ }^{1} \mathrm{H}$ NMR spectra were recorded once a week, focusing on the monomer signal at $7.058 \mathrm{ppm}$. The relative monomer content was estimated using the BHT signal at $6.98 \mathrm{ppm}$ as a constant reference (constant $=1)$. Figure 9 depicts the constant BHT signal in all measured samples during the monomer release study of the $2000 \mathrm{~g} / \mathrm{mol}$ PCBA. The monomer signal marked ' $\mathrm{m}$ ' increased steadily over the seven week period.

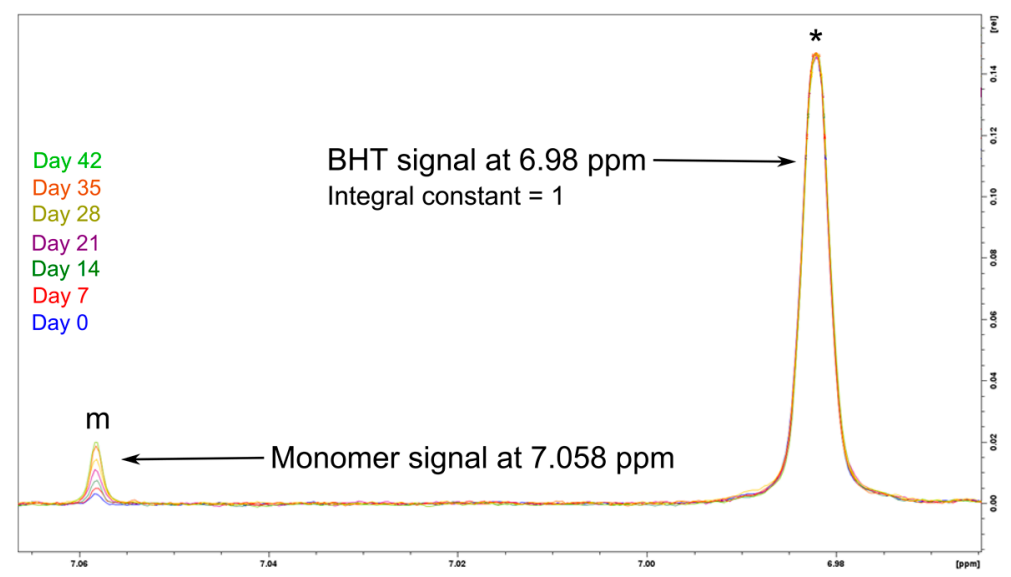

Figure 9. The ${ }^{1} \mathrm{H}$ NMR spectrum section of the monomer $(\mathrm{m})$ and BHT $\left(^{*}\right)$ signal in $2000 \mathrm{~g} / \mathrm{mol} \mathrm{PBCA}$ stored for seven weeks as solution in $\mathrm{CDCl}_{3}$. The BHT signal area $\left(^{*}\right)$ was constant during the storage, and consequently the integral value for BHT was assumed to be 1 . 
It can be assumed that the monomer residue originated from the NaOMe-derived monomer unzipping reaction (DPRP), resulting in the previously elucidated MW changes. However, the monomer release could also be a phenomenon induced by the living character of the PBCA chain progressing after the completion of the polymerization process. However, despite the living character of the PBCA as a polymer, it is essential that PBCA as a pharmaceutical excipient has a certain inherent chemical stability, especially to provide reasonable shelf-life. Thus, the end-capping of the chain termini using EBMA could potentially increase the shelf-life of PBCA as excipient by depriving PBCA of its living character and therewith preventing monomer release. The main observations made from the experimental results displayed in Figure 10 are:

1. The monomer release is indeed a progressive phenomenon for both PBCA batches, as the monomer amount clearly increased during storage;

2. The EBMA end-capping of the PBCA chains (tPBCA) inhibited the progression of the monomer release.
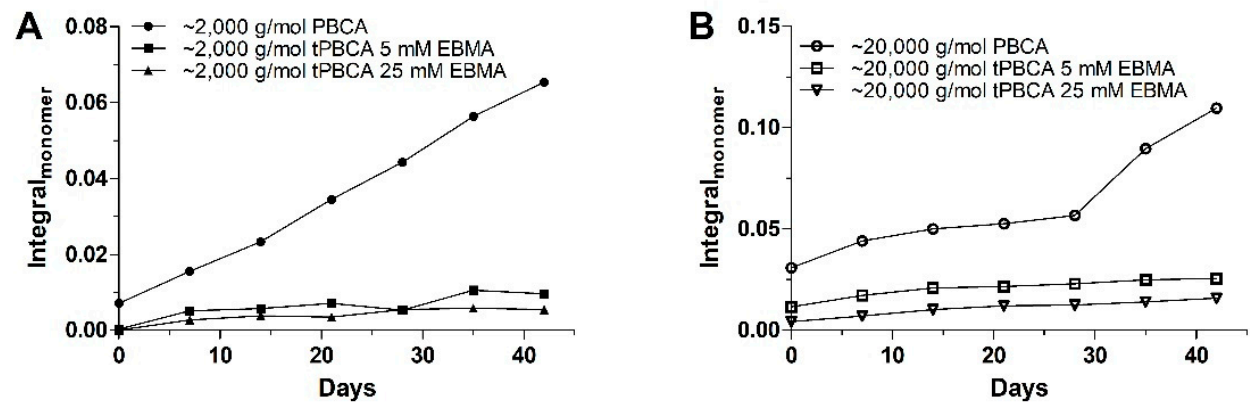

Figure 10. Monomer release monitored in ${ }^{1} \mathrm{H}$ NMR measurements at $7.058 \mathrm{ppm}(\mathrm{m})$ for PBCA and tPBCA. tPBCA was terminated using two different EBMA concentrations, $5 \mathrm{mM}$ and $25 \mathrm{mM}$. PBCA and $\mathrm{tPBCA}$ having a MW of $\sim 2000 \mathrm{~g} / \mathrm{mol}$ (A) and $\sim 20,000 \mathrm{~g} / \mathrm{mol}$ (B) were stored for seven weeks in $\mathrm{CDCl}_{3}$ solution.

This proves that the PBCA chain is truly "alive", thus also confirming the hypothesis of the monomer unzipping reaction. It also proves that the termination with EBMA deprived the PBCA chain of its living character because PBCA lost its C-H acidity at the end chain, and therefore the formation of carbanion was not possible. Consequently, the PBCA chain restructuring process (DPRP) was prevented by the end-capping with EBMA, which effectively suppressed the monomer release.

\section{Conclusions}

The process design of the anionic living polymerization of BCA in THF by varying the amounts of TFA, NaOMe and BCA demonstrated that the MW of PBCA was controllable within a range of $1000 \mathrm{~g} / \mathrm{mol}$ to $200,000 \mathrm{~g} / \mathrm{mol}$. It turned out that the key factor for MW control was the added amount of NaOMe. Characterization by APC ${ }^{\text {TM }}$ proved to be a good tool to monitor the polymerization process, while the NMR measurements confirmed the expected chemical structure. Both techniques also confirmed the postulated depolymerization-repolymerization behavior of PBCA. Stability studies on neat PBCA and EBMA-end-capped PBCA in solution were conducted over the course of seven weeks. Neat PBCA revealed a larger growth of free monomer over time due to the depolymerization, whereas the monomer growth was suppressed in the end-capped PBCA. The ongoing depolymerization of the polymer chain confirmed the living character of PBCA. The chemical instabilities of the neat polymer would cause a shelf-life reduction, thus impacting the quality of PBCA as an excipient. The present work demonstrates that low and high MW PBCA can be synthesized and end-capped as a possible means to increase the chemical stability and, hence, the shelf-life of the polymer. Increasing the shelf-life can potentially enable the diverse drug delivery applications of this biodegradable polymer. 
Author Contributions: Conceptualization, B.-L.K. and G.F.; synthesis, investigation and analysis, B.-L.K.; resources, S.O.K.; writing-original draft preparation, C.A.L. and B.-L.K.; writing-review and editing, C.A.L., B.-L.K. and S.O.K.; supervision, G.F.; project administration, G.F. and S.O.K. All authors have read and agreed to the published version of the manuscript.

Funding: This research received no external funding.

Institutional Review Board Statement: Not applicable.

Informed Consent Statement: Not applicable.

Data Availability Statement: Restrictions apply to the availability of these data. Data was obtained from AbbVie and are not available without the permission of AbbVie.

Acknowledgments: The authors thank Yeliz Tunc-Sarisozen and Cristian Cojocariu of Waters Corporation for reviewing of the manuscript, fruitful discussions and valuable input.

Conflicts of Interest: Benjamin-Luca Keller and Samuel Kyeremateng are employees of AbbVie and may own AbbVie stock. Claudia A. Lohmann is an employee of Waters Corporation and has no additional conflicts of interest to disclose. AbbVie sponsored and funded the study; contributed to the design; participated in the collection, analysis and interpretation of data, and in writing, reviewing and approval of the final publication.

\section{References}

1. Soppimath, K.S.; Aminabhavi, T.M.; Kulkarni, A.R.; Rudzinski, W.E. Biodegradable polymeric nanoparticles as drug delivery devices. J. Control Release 2001, 70, 1-20. [CrossRef]

2. Elzoghby, A.O.; Samy, W.M.; Elgindy, N.A. Albumin-based nanoparticles as potential controlled release drug delivery systems. J. Control Release 2012, 157, 68-82. [CrossRef] [PubMed]

3. Yadav, N.; Khatak, S.; Sara, U.V.S. Solid lipid nanoparticles-A review. Int. J. Appl. Pharma 2013, 5, 8-18.

4. Ling, D.; Hyeon, T. Chemical design of biocompatible iron oxide nanoparticles for medical applications. Small 2013, 9, 1450-1466. [CrossRef] [PubMed]

5. Boisselier, E.; Astruc, D. Gold nanoparticles in nanomedicine: Preparations, imaging, diagnostics, therapies and toxicity. Chem. Soc. Rev. 2009, 38, 1759-1782. [CrossRef] [PubMed]

6. Samad, A.; Sultana, Y.; Aqil, M. Liposomal drug delivery systems: An update review. Curr. Drug Deliv. 2007, 4, 297-305. [CrossRef] [PubMed]

7. Lacerda, L.; Bianco, A.; Prato, M.; Kostarelos, K. Carbon nanotubes as nanomedicines: From toxicology to pharmacology. Adv. Drug Deliv. Rev. 2006, 58, 1460-1470. [CrossRef] [PubMed]

8. Van, E.B.; Van den Mooter, G.; Augustijns, P. Top-down production of drug nanocrystals: Nanosuspension stabilization, miniaturization and transformation into solid products. Int. J. Pharm. 2008, 364, 64-75. [CrossRef]

9. Kumari, A.; Yadav, S.K.; Yadav, S.C. Biodegradable polymeric nanoparticles-based drug delivery systems. Colloids Surf. B Biointerfaces 2010, 75, 1-18. [CrossRef] [PubMed]

10. Couvreur, P.; Kante, B.; Roland, M.; Guiot, P.; Bauduin, P.; Speiser, P. Polycyanoacrylate nanocapsules as potential lysosomotropic carriers: Preparation, morphological and sorptive properties. J. Pharm. Pharmacol. 1979, 5, 331-332. [CrossRef]

11. Vauthier, C.; Dubernet, C.; Fattal, E.; Pinto-Alphandary, H.; Couvreur, P. Poly(alkylcyanoacrylates) as biodegradable materials for biomedical applications. Adv. Drug Deliv. Rev. 2003, 55, 519-548. [CrossRef]

12. Nicolas, J.; Couvreur, P. Synthesis of poly(alkyl cyanoacrylate)-based colloidal nanomedicines. Wiley Interdiscip. Rev. Nanomed. Nanobiotechnol. 2009, 1, 111-127. [CrossRef]

13. Gao, S.; Xu, Y.; Asghar, S.; Chen, M.; Zou, L.; Eltayeb, S.; Huo, M.; Ping, Q.; Xiao, Y. Polybutylcyanoacrylate nanocarriers as promising targeted drug delivery systems. J. Drug Target. 2015, 23, 481-496. [CrossRef] [PubMed]

14. P010002; Indermil ${ }^{\mathrm{TM}}$ Tissue Adhesive. U.S. Food and Drug Administration: Silver Spring, MD, USA, 2002.

15. Pifferi, G.; Santoro, P.; Pedrani, M. Quality and functionality of excipients. Farmaco 1999, 54, 1-14. [CrossRef]

16. Pifferi, G.; Restani, P. The safety of pharmaceutical excipients. Farmaco 2003, 58, 541-550. [CrossRef]

17. Eromosele, I.C.; Pepper, D.C. Anionic polymerization of butyl cyanoacrylate by tetrabutylammonium salts, Propagation rate constants. Macromol. Chem. Phys. 1989, 190, 3095-3103. [CrossRef]

18. Limouzin, C.; Caviggia, A.; Ganachaud, F.; Hemery, P. Anionic Polymerization of n-Butyl Cyanoacrylate in Emulsion and Miniemulsion. Macromolecules 2003, 36, 667-674. [CrossRef]

19. Almalik, A.; Donno, R.; Cadman, C.J.; Cellesi, F.; Day, P.J.; Tirelli, N. Hyaluronic acid-coated chitosan nanoparticles: Molecular weight-dependent effects on morphology and hyaluronic acid presentation. J. Control Release 2013, 172, 1142-1150. [CrossRef] [PubMed]

20. Mittal, G.; Sahana, D.K.; Bhardwaj, V.; Kumar, M.N.V.R. Estradiol loaded PLGA nanoparticles for oral administration: Effect of polymer molecular weight and copolymer composition on release behavior in vitro and in vivo. J. Control Release 2007, 119, 77-85. [CrossRef] [PubMed] 
21. Gorner, T.; Gref, R.; Michenot, D.; Sommer, F.; Tran, M.N.; Dellacherie, E. Lidocaine-loaded biodegradable nanospheres. I. Optimization Of the drug incorporation into the polymer matrix. J. Control Release 1999, 57, 259-268. [CrossRef]

22. Ryan, B.; McCann, G. Novel sub-ceiling temperature rapid depolymerization-repolymerization reactions of cyanoacrylate polymers. Macromol. Chem. Phys. 1996, 17, 217-227. [CrossRef]

23. Pepper, D.C.; Ryan, B. Initiation Processes in Polymerization of Alkyl Cyanoacrylates by Tertiary Amines: Inhibition by Strong Acids. Macromol. Chem. Phys. 1983, 184, 383-394. [CrossRef]

24. Costa, G.; Cronin, D.C.; Pepper, D.C.; Loonan, C. Termination and transfer by acids in the pyridineinitiated. polymerization of butyl cyanoacrylate. Euro Polym. J. 1983, 19, 939-945. [CrossRef]

25. Odian, G. Principles of Polymerization, 4th ed.; John Wiley \& Sons, Inc.: Hoboken, NJ, USA, 2004; pp. 412-436. [CrossRef]

26. Donnelly, E.F.; Johnston, D.S.; Pepper, D.C. Ionic and zwitterionic polymerization of $n$-alkyl 2-cyanoacrylates. Polym. Lett. Ed. 1977, 15, 399-405. [CrossRef]

27. Canale, A.J.; Goode, W.E.; Kinsinger, J.B.; Panchak, J.R.; Kelso, R.L.; Graham, R.K. Methyl $\alpha$-cyanoacrylate I Free-radical homopolymerization. J. Appl. Polym. Sci. 1960, 4, 231-236. [CrossRef]

28. Han, M.G.; Kim, S.; Liu, S.X. Synthesis and degradation behavior of poly(ethyl cyanoacrylate). Polym. Degrad. Stab. 2008, 93, 1243-1251. [CrossRef]

29. Miele, E.; Spinelli, G.P.; Miele, E.; Tomao, F.; Tomao, S. Albumin-bound formulation of paclitaxel (Abraxane ABI-007) in the treatment of breast cancer. Int. J. Nanomed. 2009, 4, 99-105. [CrossRef]

30. Robello, D.R.; Eldridge, T.D.; Swanson, M.T. Degradation and Stabilization of Polycyanoacrylates. J. Polym. Sci. 1999, 37, 4570-4581. [CrossRef]

31. Leonard, F.; Kulkarni, R.K.; Brandes, J.N.; Cameron, J. Synthesis and Degradation of Poly(alkyl-cyanoacrylates. J. Appl. Polym. Sci. 1966, 10, 259-272. [CrossRef]

32. Pirker, S.; Kruse, J.; Noe, C.; Langer, K.; Zimmer, A.; Kreuter, J. Characterization of polybutyleyanoacrylate nanoparticles. Part II: Determination of polymer content by NMR analysis. Int. J. Pharm. 1995, 128, 189-195. [CrossRef]

33. Wohlgemuth, M.; Machtle, W.; Mayer, C. Improved preparation and physical studies of polybutylcyanoacrylate nanocapsules. J. Microencapsul. 2000, 17, 437-448. [CrossRef]

34. Mulik, R.; Mahadik, K.; Paradkar, A. Development of curcuminoids loaded poly(butyl)cyanoacrylate nanoparticles: Physicochemical characterization and stability study. Eur. J. Pharm. Sci. 2009, 37, 395-404. [CrossRef]

35. Mayer, C. NMR Studies of Nanoparticles. Annu. Rep. NMR Spectrosc. 2005, 55, 258. [CrossRef]

36. Szanka, I.; Szanka, A.; Kennedy, J. Robbery Wound Closure Adhesives. II. Initiators for and Initiation of 2-Octyl Cyanoacrylate Polymerization. J. Polym. Sci. 2015, 53, 1652-1659. [CrossRef]

37. Kohsaka, Y.; Ishihara., S.; Kitayama, T. Termination of Living Anionic Polymerization of Butyl Acrylate with alpha(Chloromethyl)acrylate for End-Functionalization and Application to Evaluation of Monomer Reactivity. Macromol. Chem. Phys. 2015, 216, 1534-1539. [CrossRef] 